\title{
Determination of Free Tryptophan in Plasma and Its Clinical Applications
}

\author{
By Yasuyo Hijikata
}

3rd Department of Internal Medicine,

Katsuko Hara

Central Laboratory,

Yasuko Shiozaki

3rd Department of Internal Medicine,

Kenjiro Murata

Clinical Laboratory of Medicine and

Yoshiko Sameshima

3rd Department of Internal Medicine,

Kansai Medical University, I Fumisonocho, Moriguchi, Osaka 570, Japan

(Received August 23/December 5. 1983)

Summary: Free tryptophan in plasma was separated by centrifugation through an Amicon ultrafiltration membrane cone. The value obtained without control of $\mathrm{pH}$ was found to be lower than that obtained with control of pH by an improved method (Hijikata et al. (1981) Anal. Biochem. 118, 10-16).

For determination of the total tryptophan concentration in the plasma, high performance liquid chromatography (HPLC) was better than the method of Denckla Dewey as modified by Bloxam \& Warren ((1974) Anal. Biochem. 60,621-625), as judged on the basis of sensitivity, recovery rate and coefficient of variance. The total tryptophan concentration in the plasma determined by HPLC was lower than that determined by the Bloxam \& Warren method.

The total tryptophan concentration ( $t$-Trp), free tryptophan concentration (f-Trp) and f-Trp/t-Trp ratio were $55.8 \pm 10.2 \mu \mathrm{mol} / \mathrm{l}, 11.6 \pm 1.5 \mu \mathrm{mol} / \mathrm{l}$ and $0.211 \pm 0.03$ (mean $\pm 1 \mathrm{SD}$ ) respectively, in healthy subjects (controls). No significant difference was observed between the values of controls and those of patients with liver cirrhosis, hepatocellular carcinoma, liver cirrhosis with hepatocellular carcinoma and hepatic encephalopathy of liver cirrhosis without bleeding. But in liver cirrhosis with bleeding, free tryptophan concentration (f-Trp, $48.0 \pm 23.3 \mu \mathrm{mol} / \mathrm{l}, \mathrm{p}<0.001)$ and $\mathrm{f}-\operatorname{Trp} / \mathrm{t}-\operatorname{Trp}$ ratio $(0.645 \pm 0.289, \mathrm{p}<0.001)$ were significantly higher than those of controls. In fulminant hepatitis free tryptophan concentration, (f-Trp, $106.6 \pm 79.9$ $\mu \mathrm{mol} / \mathrm{l}, \mathrm{p}<0.02)$, and $\mathrm{f}-\operatorname{Trp} / \mathrm{t}-\operatorname{Trp}$ ratio $(0.973 \pm 0.017, \mathrm{p}<0.001)$ were significantly higher than those of controls, and free tryptophan concentration (f-Trp) and $\mathrm{f}-\operatorname{Trp} / \mathrm{t}-\operatorname{Trp}$ ratio $(\mathrm{p}<0.005)$ were significantly higher than in liver cirrhosis with bleeding. In other words the increase of free tryptophan concentration in plasma may be related to the bleeding, and in fulminant hepatitis the binding ability of free tryptophan to albumin may decrease.

In the examined cases of liver cirrhosis, the correlation of the concentration of plasma tryptophan with those of other amino acids and indicators of liver function was changed when hepatocellular carcinoma was also present. 


\section{Bestimmung des freien Tryptophan im Plasma und ihre klinische Anwendung}

Zusammenfassung: Freies Tryptophan im Plasma wurde durch Zentrifugation durch einen Amicon Ultrafiltrations-Membrankegel abgetrennt. Der ohne $\mathrm{pH}$-Kontrolle erhaltene Wert war niedriger als der mit $\mathrm{pH}-$ Kontrolle nach einer verbesserten Methode nach Hijikata ((1981) Anal. Biochem. 118, 10-16) erhältene.

Für die Bestimmung des gesamten Tryptophan im Plasma war die Hochleistungsflüssigchromatographie (HPLC) besser geeignet als die Methode von Denckla Dewey, modifiziert von Bloxam \& Warren ((1974) Anal. Biochem. 60,621-625). Dies wurde durch Untersuchung der Empfindlichkeit, der Wiederfindung und der Präzision festgestellt; das durch HPLC bestimmte gesamte Tryptophan im Plasma war niedriger als das mit der Methode von Bloxam \& Warren bestimmte.

Bei gesunden Kontrollpersonen betrug die Konzentration des gesamten Tryptophan (t-Trp) 55,8 $\pm 10,2$ $\mu \mathrm{mol} / \mathrm{l}$, die des freien Tryptophan (f-Trp) $11,6 \pm 1,5 \mu \mathrm{mol} / \mathrm{l}$ und das Verhältnis beider (f-Trp/t-Trp) 0,211 \pm $0,03(\bar{x} \pm s)$. Es bestand keine signifikante Differenz zwischen den Werten der gesunden Kontrollpersonen und denen von Patienten mit Lebercirrhose, hepatozellulärem Carcinom, Lebercirrhose bei gleichzeitig bestehendem hepatozellulären Carcinom und hepatischer Encephalopathie bei Lebercirrhose ohne Blutung. Bei Lebercirrhose mit Blutung waren jedoch freies Tryptophan $(48,0 \pm 23,3 \mu \mathrm{mol} / \mathrm{l}, \mathrm{p}<0,001)$ und f-Trp/t-TrpQuotient $(0,645 \pm 0,289, \mathrm{p}<0,001)$ signifikant höher als bei den Kontrollpersonen. Bei fulminanter Hepatitis waren freies Tryptophan $(106,6 \pm 79,9 \mu \mathrm{mol} / 1, \mathrm{p}<0,02)$ und der $\mathrm{f}-\operatorname{Trp} / \mathrm{t}$-Trp-Quotient $(0,973 \pm 0,017$, $p<0,01)$ signifikant höher als bei den Kontrollpersonen sowie signifikant höher $(p<0,005)$ als bei Lebercirrhose mit Blutung. Der Anstieg der Konzentration des freien Tryptophan im Plasma könnte zur Blutung in Beziehung stehen, und bei fulminanter Hepatitis könnte die Bindungsfähigkeit von Tryptophan an Albumin verringert sein.

In den untersuchten Fällen von Lebercirrhose waren die Korrelationen der Konzentration von Tryptophan im Plasma mit denen der anderen Aminosäuren und Indikatoren der Leberfunktion verändert, wenn gleichzeitig ein hepatozelluläres Carcinom vorlag.

\section{Introduction}

Although the pathogenesis of hepatic encephalopathy in severe hepatic failure is not clearly understood, 2-oxoglutaramate (2), ammonia (3), free fatty acids (4-7), methylmercaptan (7) and other false neurotransmitters $(8-12)$ are reported to be causes of hepatic coma.

Tryptophan, the precursor of the putative neurotransmitter and serotonin, are reported to be involved in hepatic encephalopathy $(13,14)$. But the plasma tryptophan concentration often fluctuates in hepatic encephalopathy, and so it is difficult to determine whether tryptophan is directly related to hepatic encephalopathy.

Munro reported that in severe hepatic failure, the concentration of branched chain amino acids decreased and that the competitive inhibition of the passage of tryptophan through the blood brain barrier by other amino acids was abolished, resulting in increased tryptophan and serotonin concentrations in the brain and production of encephalopathy (15).

Tryptophan is the only amino acid that is present in the blood in two states, free and bound to albumin (16) and free tryptophan is thought to pass through blood brain barrier. However, a standard method for the determination of free tryptophan in the plasma has not been established. Recently, we improved the method for separation of free tryptophan in plasma by centrifugation through Amicon ultrafiltration cones (17).

In this method, it is important to control the pH during centrifugation, in order to maintain the equilibrium between free and bound tryptophan. In previous reports, the plasma tryptophan is assayed without separating the tryptophan $(16,18-20)$, so that contaminants in the sample influence the value for the tryptophan concentration. Therefore, further application of high performance liquid chromatography (HPLC) is useful for the specific determination of tryptophan in the plasma. In fact the total tryptophan concentration in the plasma of patients with liver disease determined by the method of Denckla Dewey as modified by Bloxam \& Warren, in which tryptophan is not separated (1), tended to be higher than those determined by HPLC.

Recently, Beck \& Hesselgren (21) also suggested the usefulness of HPLC for determination of tryptophan. But they obtained the free tryptophan fraction by ultrafiltration under pressure not by centrifugation. 
In this work, we determined the plasma free tryptophan of patients with hepatic diseases by HPLC, after separation of free tryptophan from bound tryptophan by our improved method (17), and found that free tryptophan in plasma increased in patients with a tendency to bleeding.

\section{Materials and Methods}

\section{Patients studied}

Studies were carried out on 60 subjects. They were divided into 7 groups, classified as follows:

1) 10 healthy volunteers as controls,

2) 17 biopsy-proven cirrhotics without hepatic encephalopathy (liver cirrhosis),

3) 13 cirrhotics with hepatocellular carcinoma without hepatic encephalopathy (liver cirrhosis + hepatocellular carcinoma) (10 proven by biopsy; 3 on the basis of medical history and clinical picture),

4) 6 biopsy-proven cirrhotics in grade 2 or 3 hepatic encephalopathy without bleeding tendency,

5) 6 cirrhotics with bleeding tendency without hepatic encephalopathy ( 3 autopsy proven, 3 biopsy-proven, 5 cases with rupture of oesophagus varices and 1 with intestinal bleeding),

6) 5 hepatocellular carcinoma ( 4 biopsy-proven, 1 by clinical picture),

7) 3 autopsy-proven fulminant hepatitis in grade 3 or 4 hepatic encephalopathy (fulminant hepatitis)

The grade of encephalopathy was assessed according to the classification of Trey et al. (22). All controls and subjects with liver cirrhosis, liver cirrhosis + hepatocellular carcinoma and hepatocellular carcinoma fasted overnight before sampling. For liver cirrhosis. with encephalopathy but no bleeding tendency with manifested hepatic encephalopathy samples were obtained before starting special treatment for hepatic encephalopathy. With liver cirrhosis with bleeding tendency and fulminant hepatitis, samples were collected as soon as possible after admission.

\section{Collection of blood and preparation of plasma}

Collection of blood and further procedures were performed basically as described previously (17). Human blood was collected from the antecubital vein into a heparinized $(143 \mathrm{U} / \mathrm{ml})$ tube and centrifuged at $3000 \mathrm{~g}$ for $10 \mathrm{~min}$ at room temperature $\left(25^{\circ} \mathrm{C}\right)$. The plasma was then rapidly transferred to a test tube $(10 \times 120$ $\mathrm{mm}$ glass tube) and sealed with parafilm. In order to dispel the air, the parafilm was pierced twice with a pin and a mixture of 0.05 $\mathrm{CO}_{2}$ and $0.95 \mathrm{~N}_{2}$ gas introduced into the tube at a rate of about 60 $\mathrm{ml} / \mathrm{min}$ for 10 seconds through one of the holes. Then, the pinholes were sealed as rapidly as possible by covering the tube with another piece of parafilm to avoid the escape of $\mathrm{CO}_{2}$ from plasma.

\section{Ultrafiltration by centrifugation of plasma}

Fresh plasma prepared as described above was incubated at $37^{\circ} \mathrm{C}$ for $5 \mathrm{~min}$, then $0.5 \mathrm{ml}$ was transferred to a CF-50 Centriflo membrane cone (Amicon) (nominal molecular weight cut-off: 50000) inserted into a centrifuge tube. We used CF-50 cones as supplied, without soaking them in water to remove the glycerol plasticizer. The cone was sealed with parafilm and the air in the cone was displaced with $0.05 \mathrm{CO}_{2}$ and $0.95 \mathrm{~N}_{2}$ gas. The tube was centrifuged for 30 seconds at $3000 \mathrm{~g}$ at $37^{\circ} \mathrm{C}\left( \pm 1^{\circ} \mathrm{C}\right)$ using a thermostat
Kubota KR-700 centrifuge. The filtrate was then transferred to a small tube by a micropipet with which the volume (several microliters) was measured, sealed tightly with parafilm, and quickly frozen $\left(-90^{\circ} \mathrm{C}\right)$ until assay. After removing the first filtrate the cone was recentrifuged for 10 seconds at $3000 \mathrm{~g}$ and the second filtrate was obtained as above. Four further centrifugations were carried out until six filtrates were collected. Ultrafiltration of plasma without control of $\mathrm{pH}$ was carried out as above except that the cone was not sealed with parafilm and was centrifuged at $1000 \mathrm{~g}$ instead of $3000 \mathrm{~g}$.

Measurement of $\mathrm{pH}$ and $\mathrm{pCO}_{2}$ in plasma during centrifugation

We prepared six cones each containing $0.5 \mathrm{ml}$ of plasma, and displaced the air with $0.05 \mathrm{CO}_{2}$ and $0.95 \mathrm{~N}_{2}$ gas. After centrifugation for 30 seconds, one of the six samples was applied to an automatic blood gas analyser system (Acid Base Laboratory ABL-2 operating, Radiometer Copenhagen) to determine the $\mathrm{pH}$ and $\mathrm{pCO}_{2}$. The other samples in the cones were subjected to $\mathrm{pH}$ and $\mathrm{pCO}_{2}$ measurements after further centrifugation for successive $10 \mathrm{se}-$ cond periods.

\section{Determination of amino acid concentrations}

Tryptophan and other amino acids were determined by HPLC as reported in our previous papers $(17,23) . D, L$-Norleucine was used as internal standard. In the comparison study, the Bloxam Warren method (1) for plasma tryptophan was also carried out.

\section{Results}

Effect of $\mathrm{pH}$ of plasma during centrifugation on the free tryptophan concentration

Ultrafiltrate was prepared by centrifuging plasma in the cones without $\mathrm{pH}$ control, or $\mathrm{pH}$ was controlled by filling the cones with $0.05 \mathrm{CO}_{2}$ and $0.95 \mathrm{~N}_{2}$ gas and sealing them with parafilm. The rates of filtration at $1000 \mathrm{~g}$ without control of $\mathrm{pH}$ and at $3000 \mathrm{~g}$ with control of $\mathrm{pH}$ were similar.

As shown in figure 1, the value for tryptophan concentration in the filtrate with $\mathrm{pH}$ control was always higher than without $\mathrm{pH}$ control at the same total volume of filtrate. Next we examined whether the $\mathrm{pH}$ or $\mathrm{pCO}_{2}$ of plasma in the cone influenced the tryptophan value in the filtrate (fig. 2). In plasma centrifuged as described above with $\mathrm{CO}_{2}$ in $\mathrm{N}_{2}$ in place of air, the plasma $\mathrm{pH}$ scarcely changed, whereas on filtration without $\mathrm{pH}$ control, the $\mathrm{pH}$ increased and the $\mathrm{pCO}_{2}$ decreased.

If we define free tryptophan of plasma as the tryptophan concentration in the first filtrate by our method with $\mathrm{pH}$ control (17), then the free tryptophan of plasma of one healthy subject was $14.6 \mu \mathrm{mol} / \mathrm{l}$, whereas the free tryptophan of the same subject was $5.4 \mu \mathrm{mol} / 1$ when the ultrafiltrate was obtained by centrifugation of plasma for $20 \mathrm{~min}$ at $800 \mathrm{~g}$ without $\mathrm{pH}$ control $(16,18-20)$ (data not shown). 


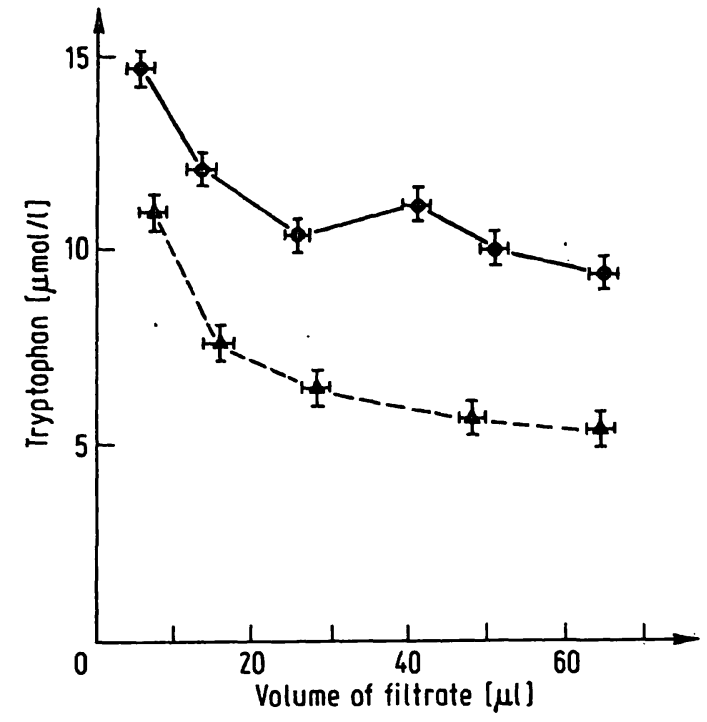

Fig. 1. Change of tryptophan concentration in the filtrate during centrifugation of plasma in a cone with and without $\mathrm{pH}$ control.

For $\mathrm{pH}$ control (solid line), after incubation for $5 \mathrm{~min}$ at $37^{\circ} \mathrm{C}, 0.5 \mathrm{ml}$ of plasma was transferred to a CF-50 Centriflo membrane cone (Amicon) inserted into a centrifuge tube. The cone was sealed with parafilm and the air in the cone was displaced with $0.05 \% \mathrm{CO}_{2}$ and $0.95 \mathrm{~N}_{2}$ gas as described under materials and methods. The cone was centrifuged at $3000 \mathrm{~g}$ for 30 seconds at $37^{\circ} \mathrm{C}$ and then all the filtrate was promptly transferred to a small test tube using a micropipet with which the volume was measured. The tube was sealed tightly with parafilm and stored at $-90^{\circ} \mathrm{C}$ until assay. Samples obtained in the same way by 5 subsequent centrifugations for 10 second periods were also assayed. Without pH control (broken line), $0.5 \mathrm{ml}$ of plasma was transferred to a cone and centrifuged without parafilm at $1000 \mathrm{~g}$ at $37^{\circ} \mathrm{C}$. Other procedures were as with $\mathrm{pH}$ control. Standard deviations of the volume of filtrate and observed tryptophan concentration in four different experiments on the same specimen of normal plasma are shown by horizontal and vertical bars, respectively. The tryptophan concentration of each fraction is plotted against the cumulative volume of filtrate.

Comparison of the HPLC and Bloxam Warren methods for plasma tryptophan determination

\section{Recovery rate}

Samples of $0.9 \mathrm{ml}$ of plasma containing ca. $30 \mu \mathrm{mol} / 1$ tryptophan were mixed with $0.1 \mathrm{ml}$ of $50 \mu \mathrm{mol} / \mathrm{h}$ or $200 \mu \mathrm{mol} / \mathrm{l}$ tryptophan solution and the tryptophan concentrations of the mixtures were determined by HPLC and the Bloxam Warren method (1) (tab. 1).

By HPLC, the observed values coincided with the calculated values, but by the Bloxam Warren method, values were higher than expected, especially at the lower concentration of tryptophan.

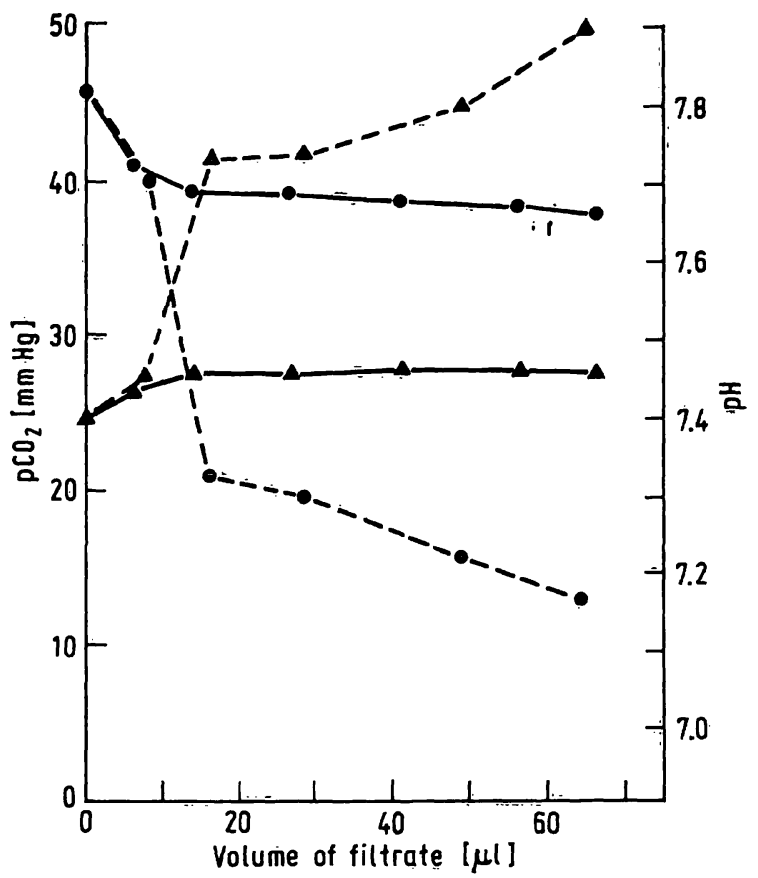

Fig. 2. Changes of $\mathrm{pH}$ and $\mathrm{pCO}_{2}$ of plasma in the cone during centrifugation with and without $\mathrm{pH}$ control. The same plasma as for fig. 1 was used after incubation for $10 \mathrm{~min}$. (No significant difference was observed between the plasma samples at the beginning of the experiments in fig. 1 and fig. 2.). The plasma was transferred to 12 cones $(6$ cones with, and 6 without $\mathrm{pH}$ control) in two centrifuges. Centrifugation was carried out as for fig. 1 and the plasma in each cone was used to measure the $\mathrm{pH}(\Delta)$ and $\mathrm{pCO}_{2}$ (๑). Values with $(\longrightarrow)$ and without $(--) \mathrm{pH}$ control are shown.

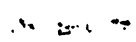

Tab. 1. Comparison of recovery rates of tryptophan in the HPLC and Bloxam Warren method.

Samples of $0.9 \mathrm{ml}$ of plasma containing ca. $30 \mu \mathrm{mol} / \mathrm{l}$ tryptophan were mixed with $0.1 \mathrm{ml}$ of $50 \mu \mathrm{mol} / \mathrm{l}(\mathrm{A})$ or $200 \mu \mathrm{mol} / \mathrm{l}(\mathrm{B})$ tryptophan solution and the tryptophan concentration was determined by the HPLC and Bloxam Warren method. I and II are different plasmas. Values are recovery rates (\%) of added tryptophan.

\begin{tabular}{lrrrrr}
\hline & \multicolumn{2}{c}{ HPLC } & \multicolumn{2}{c}{ Bloxaim Warren } \\
& A & B & A & \multicolumn{1}{c}{ B } \\
\hline \multirow{2}{*}{ Recovery rate (\%) } & I & 98 & 100 & 180 & 130 \\
& II & 103 & 100 & 270 & 140 \\
\hline
\end{tabular}

\section{Coefficient of variation (CV)}

The CV was smaller by HPLC $(0.82 \%, n=10)$ than by the Bloxam Warren method $(1.75 \%, \tilde{n}=10)(\mathrm{da}-$ ta not shown). 
Effect of coexistent amino acids on tryptophan determination

As shown in table 2, two kinds of amino acid mixtures, one similar in composition to that in normal plasma (A) and the other similar to that in liver disease (B), were prepared and their tryptophan concentrations were determined by HPLC and the Bloxam Warren method. HPLC gave almost the expected values, but the Bloxam Warren method did not.

Tab. 2. Comparison of values for tryptophan concentrations of two amino acid mixtures measured by the HPLC and Bloxam Warren method.

Two amino acid mixtures, one with the amino acid composition of normal plasma (A) and the other with that of plasma in liver disease (B), were prepared and their tryptophan concentrations were determined by the HPLC and Bloxam Warren method.

A: $\operatorname{Trp} 10$, Val 200, Met 50, le 50, Leu 100, Tyr 50, Phe $50 \mu \mathrm{mol} / 1$.

B: Trp 46, Val 200, Met 70, Ile 40, Leu 100, Tyr 180 , Phe $100 \mu \mathrm{mol} / \mathrm{l}$.

\begin{tabular}{lll}
\hline & \multicolumn{2}{l}{$\begin{array}{l}\text { Tryptophan concentration } \\
\text { observed in }(\mu \mathrm{mol} / \mathrm{l})\end{array}$} \\
& A & B \\
\hline HPLC & $10.0 \pm 0.1$ & $45.9 \pm 0.3$ \\
Bloxam Warren & $8.0 \pm 0.8$ & $65.4 \pm 1.2$ \\
\hline
\end{tabular}

Comparison of the total tryptophan in patients measured by HPLC and the Bloxam Warren method

In all samples tested, values by the Bloxam Warren method were higher than those by HPLC. They were especially high in cases of fulminant hepatitis (tab. 3).

'Tab. 3. Comparison of total tryptophan in plasma of cases of liver diseases by HPLC and Bloxam Warren method.

\begin{tabular}{lll}
\hline Diagnosis & \multicolumn{2}{l}{$\begin{array}{l}\text { Total tryptophan observed } \\
(\mu \mathrm{mol} / \mathrm{l})\end{array}$} \\
& HPLC & Bloxam Warren \\
\hline Control, healthy subjẹt & 37.1 & 44.5 \\
Hepatocellular carcinoma & 24.6 & 30.2 \\
Fulminant hepatitis & 53.3 & 76.1 \\
Fulminant hepatitis & 27.0 & 31.4 \\
Liver cirrhosis & 74.1 & 89.6 \\
Acute hepatitis (acute type) & 60.6 & 64.6 \\
\hline
\end{tabular}

Total tryptophan (t-Trp), free tryptophan (f-Trp) and $f$-Trp/t-Trp ratio in plasma of patients with various liver diseases

Next we determined the ratio $\mathrm{f}-\mathrm{Trp} / \mathrm{t}-\mathrm{Trp}$, which is especially high in severe cases of liver diseases, using the total and free tryptophan for reference. Table 4 shows the values for total tryptophan ( $t-\operatorname{Trp})$, free

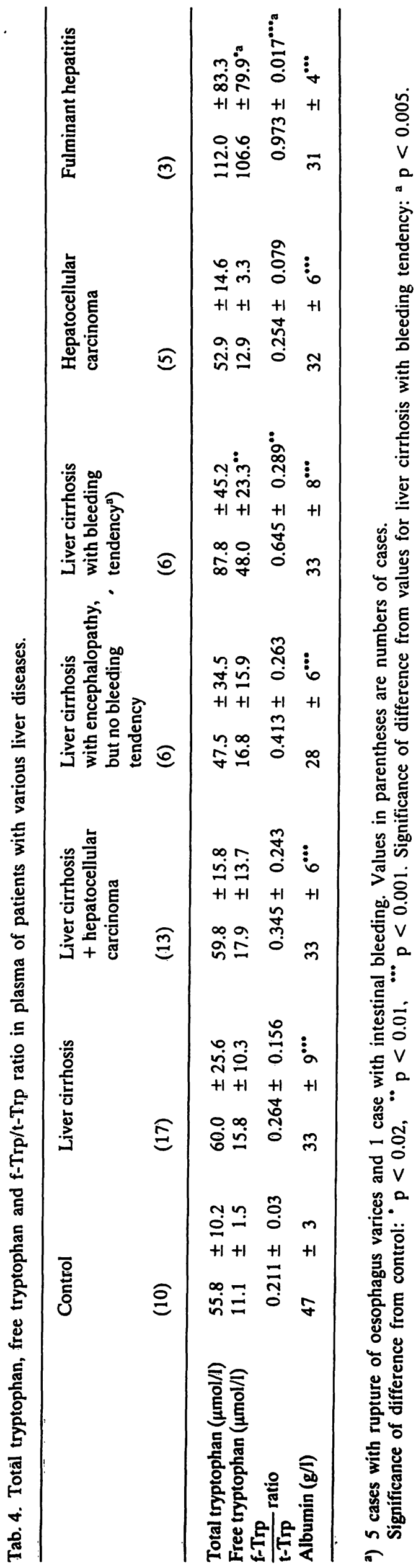


tryptophan (f-Trp) and f-Trp/t-Trp ratio in the plasma of cases of various liver diseases determined by ultrafiltration-HPLC. The values for cases' of liver cirrhosis, liver cirrhosis + hepatocellular carcinoma, liver cirrhosis with encephalopathy but no bleeding tendency and hepatocellular carcinoma were not significantly different from the control values. But in cases of liver cirrhosis with bleeding tendency, free tryptophan and $\mathrm{f}-\mathrm{Trp} / \mathrm{t}-\mathrm{Trp}$, values were significantly higher than those of the controls $(p<0.01)$.

In 3 cases of fulminant hepatitis total tryptophan varied greatly, being $215.2,109.6$ and $11.3 \mu \mathrm{mol} / 1$ in spite of comparatively similar values for the albumin concentrations ( 30,36 and $26 \mathrm{~g} / 1$ respectively). It is interesting that the $f-T r p / t-\operatorname{Trp}$ were $0.960,0.932$ and 0.972 , indicating that almost all the tryptophan was in the free state even at very low concentrations of total tryptophan. Our results provided no information on the relation between free fatty acids and free tryptophan, 'because the free fatty acids concentration was determined in only the first case (1120 $\mu \mathrm{mol} / \mathrm{l})$.

For reference purposes, the values for albumin, free fatty acids, free tryptophan and total tryptophan in cases of various liver diseases $(n=9)$ were examined for possible correlations. Only free fatty acids and albumin showed a significant relationship ( $\mathrm{r}=$ $-0.861, p<0.01$ ) (fig. 3): no relationship was observed between free fatty acids and free or total tryptophan (data not shown). Since the values for free tryptophan and $\mathrm{f}-\mathrm{Trp} / \mathrm{t}$-Trp ratio in cases of fulminant hepatitis (all of which showed a tendency for bleeding), were significantly higher than those in liver cirrhosis with bleeding tendency $(p<0.005)$, the binding ability of albumin to free tryptophan might be changed in fulminant hepatitis.

\section{Relationship between plasma tryptophan and indica- tors of liver function in plasma, or between plasma tryptophan and plasma free amino acids other than tryptophan}

In some examples, involving a significant number of cases the relationship was tested in detail (tab. 5). Close correlation was observed between total and free tryptophan in liver cirrhosis but not in liver cirrhosis + hepatocellular carcinoma. On the other hand, free tryptophan and $\mathrm{f}-\operatorname{Trp} / \mathrm{t}-\operatorname{Trp}$ were closely related in both liver cirrhosis and liver cirrhosis + hepatocellular carcinoma. It is interesting that the correlation between alkaline phosphatase and free tryptophan or $\mathrm{f}-\mathrm{Trp} / \mathrm{t}-\mathrm{Trp}$ ratio increased when liver cirrhosis was combined with hepatocellular carcinoma.

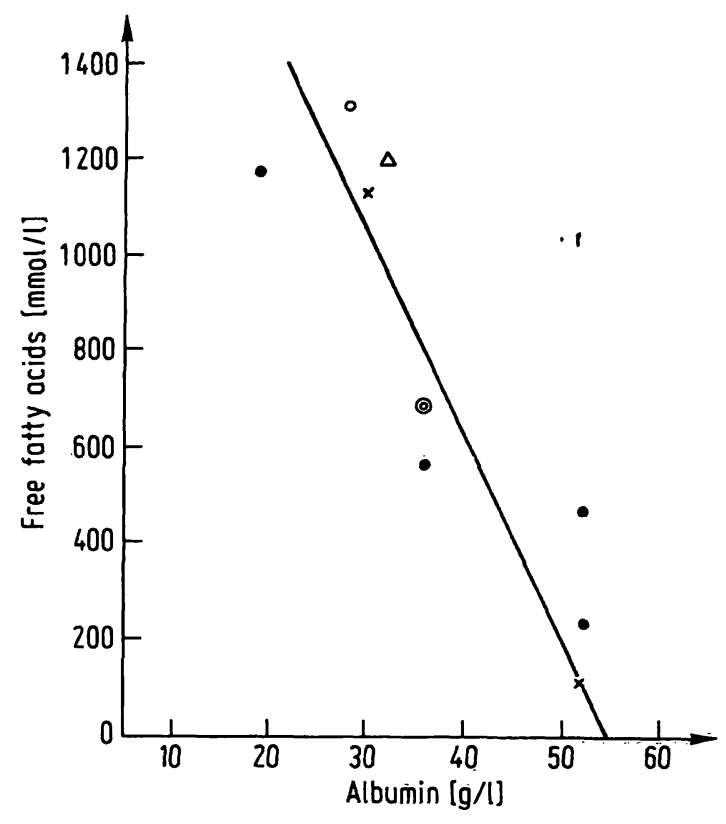

Fig. 3. Relationship between free fatty acids and albumin in plasma of patients with liver diseases.

- liver cirrhosis. $\Delta$ liver cirrhosis coma, 0 liver cirrhosis varix ${ }^{*}$ O liver cirrhosis + hepatocellular carcinoma, $x$ fulminant hepatitis. -

Significant relations were not observed between free fatty acids and free or total tryptophan and between albumin and free or total tryptophan. ": case of rupture of oesophagus varix in liver cirrhosis. $\mathrm{r}=-0.861 ; \mathrm{p}<0.01$.

\section{Discussion}

Many studies have been reported $(18,24-26)$ on the separation of free tryptophan from plasma, but the results were not satisfactory because equilibrium between free tryptophan and bound tryptophan changed during separation of the free tryptophan fraction.

Ultrafiltration of plasma in Amicon membrane cones with control of $\mathrm{pH}$ was successful and convenient for obtaining the free tryptophan fraction, and this method in combination with HPLC was better for determination of free tryptophan than any method reported already $(16,18-20)$. In this work we examined the effect of $\mathrm{pH}$ of plasma during centrifugation on the free tryptophan concentration of the filtrate. Without control of $\mathrm{pH}$ during centrifugation, the plasma $\mathrm{pCO}_{2}$ in the cone decreases and the plasma $\mathrm{pH}$ gradually increases. When the cone was filled with $0.05 \mathrm{CO}_{2}$ and $0.95 \mathrm{~N}_{2}$ gas, the $\mathrm{pCO}_{2}$ and $\mathrm{pH}$ remained almost constant and the observed free tryptophan concentration in the filtrate was higher than that without $\mathrm{pH}$ control. 
Tab. 5. Relationships of plasma tryptophan concentrations with indicators of liver function and plasma amino acid concentrations.

\begin{tabular}{|c|c|c|c|c|c|c|c|c|c|}
\hline & \multicolumn{3}{|c|}{ Liver cirrhosis } & \multicolumn{3}{|c|}{$\begin{array}{l}\text { Liver cirrhosis } \\
+ \text { hepatocellular carcinoma }\end{array}$} & \multicolumn{3}{|c|}{ Hepatocellular carcinoma } \\
\hline & (17) & & & (13) & & & (5) & & \\
\hline & t-Trp & f-Trp & $\frac{f-\operatorname{Trp}}{t-\operatorname{Tr} p}$ & $t-T r p$ & f-Trp & $\frac{f-\operatorname{Trp}}{t-\operatorname{Trp}}$ & $\mathrm{t}-\operatorname{Trp}$ & f-Trp & $\frac{f-\operatorname{Trp}}{t-\operatorname{Trp}}$ \\
\hline Free tryptophan (f-Trp) & $0.602^{\cdots \cdots}$ & & & & & & & & \\
\hline$\frac{f-\operatorname{Trp}}{\operatorname{Trp}}$ & & $0.760^{-\cdots}$ & & & $0.954^{\cdots \cdots}$ & & & & \\
\hline $\begin{array}{l}\text { t-Trp } \\
\text { Total amino acids }{ }^{2} \text { ) }\end{array}$ & & & $0.493^{\circ}$ & & & & & & \\
\hline Isoleucine & & & & $0.526^{\circ \ldots \bullet}$ & & & & & \\
\hline Methionine & & & $-0.581^{\circ \bullet}$ & & & & & & \\
\hline Tyrosine & & & $-0.415^{\circ}$ & & $0.701^{\circ \cdots \bullet}$ & $0.766^{\circ \cdots}$ & $0.910^{\circ}$ & & \\
\hline $\begin{array}{l}\text { Phenylalanine } \\
\text { Lysine }\end{array}$ & $0.585^{\circ}$ & & $-0.541^{\circ}$ & & & & & $0.965^{* * *}$ & \\
\hline Citrulline & & $0.471^{\circ}$ & & & & & & & \\
\hline Glycine & & & & & $0.486^{\circ}$ & & & & \\
\hline Alanine & & & & & & & $0.817^{\circ}$ & $0.886^{\circ}$ & \\
\hline Cysteine & & & $-0.632^{\cdots \cdots}$ & & & & & & \\
\hline Taurine & & $0.562^{\circ \bullet}$ & $0.576^{\circ}$ & & & & $-0.858^{\circ}$ & & \\
\hline Serine & $0.509^{\circ}$ & & $-0.414^{\circ}$ & & $0.639^{\circ \bullet}$ & $0.666^{* \bullet}$ & & $0.932^{\circ \bullet}$ & \\
\hline Histidine & $0.578^{\circ \bullet}$ & & & & $0.526^{\circ}$ & $0.521^{\circ}$ & & & \\
\hline Ornithine & $0.627^{\cdots \cdots}$ & & & & & & & & \\
\hline Arginine & & & & & • & & $0.942^{\cdots}$ & & \\
\hline Aspartate aminotransferase & & & & & & $0.665^{* \bullet}$ & & & $0.911^{*}$ \\
\hline Lactate dehydrogenase & $-0.572^{\circ}$ & & & & $0.549^{\circ}$ & $0.687^{* \ldots *}$ & & $-0.842^{\circ}$ & \\
\hline Leucine aminopeptidase & $-0.611^{\cdots \cdots}$ & & & & & $0.575^{\circ}$ & & $0.855^{\circ}$ & \\
\hline Alkaline phosphatase & & & & & $0.746^{\circ \cdots}$ & $0.821^{\ldots \ldots}$ & & & \\
\hline Total bilirubin & $0.542^{\circ}$ & & & $-0.553^{\circ}$ & & & & & \\
\hline Prothrombin time & $0.551^{\circ}$ & & & & & $0.558^{*}$ & & & \\
\hline Thrombocytes & $-0.542^{\circ}$ & & & & & & & & \\
\hline Choline esterase & & & $0.593^{\circ \bullet}$ & $-0.582^{*}$ & & & & & \\
\hline Total protein & & & & $-0.528^{\circ}$ & $-0.481^{\circ}$ & & & & $0.846^{\circ}$ \\
\hline Albumin & $0.630^{\circ \cdots}$ & $0.637^{\cdots \cdots}$ & & & & & & & \\
\hline Total cholesterol & $-0.457^{\circ}$ & & $0.626^{\cdots \cdots}$ & & $0.641^{\circ \bullet}$ & $0.604^{*}$ & $0.908^{\circ \bullet}$ & $0.811^{*}$ & \\
\hline Branched/aromatic amino acids ${ }^{b}$ ) & & & $0.536^{\circ}$ & & & & & & \\
\hline Albumin/globulin ratio & $0.500^{\circ}$ & $0.488^{\circ \bullet}$ & & & & & & & \\
\hline
\end{tabular}

Only significant values are shown. With indocyanine green test, esterified/total cholesterol, total tryptophan, valine, leucine, glutamic acid and alanine aminotransferase, no significant difference was observed. $\quad{ }^{p} p<0.05, \quad{ }^{*} p<0.02{ }^{\cdots} p<0.01 \cdots p<0.005 \quad$ a) $\mathrm{mol} / \mathrm{l}$ b) mol fraction.

Bloxam's method (27) for free tryptophan determination needs special apparatus and is inconvenient. But in our method, only displacement of the air by $\mathrm{CO}_{2}$ in $\mathrm{N}_{2}$ gas is necessary to keep the plasma $\mathrm{pH}$ and $\mathrm{pCO}_{2}$ constant. Moreover we could obtain a sample by centrifugation at $3000 \mathrm{~g}$ for 30 seconds, the minimum volume required was $5 \mu$, and tryptophan separated by HPLC could be measured without interference from other components in the plasma. Thus by our method, a sample closely approximating to that of free tryptophan in the plasma can be obtained in a short time.
The Bloxam Warren method of tryptophan determination gives an incorrect recovery, a higher $\mathrm{CV}$ than HPLC and an inaccurate value; this is because the tryptophan is not fractionated so that other amino acids and their derivatives that influence the value are present in the sample. No significant differences were found in the values of plasma total tryptophan, free tryptophan and f-Trp/t-Trp ratio in patients with liver cirrhosis, liver cirrhosis + hepatocellular carcinoma, hepatocellular carcinoma and liver cirrhosis with encephalopathy but no bleeding tendency compared with healthy controls. There are reports 
that plasma free tryptophan is significantly higher in liver cirrhosis (28), or hepatic encephalopathy of liver cirrhosis than in healthy controls $(19,29-31)$. These values were obtained, however, by measuring the tryptophan concentration in the filtrate after centrifugation without $\mathrm{pH}$ control, and without separation of tryptophan from other amino acids and components related to tryptophan which might influence the fluorescence assay of tryptophan. The fact that free tryptophan and $f-T r p / t-T r p$ ratio were found to be significantly raised in cases of liver cirrhosis with bleeding tendency might be due to reabsorption of blood from the alimentary tract.

Our results do not necessarily show that bleeding enhances the free tryptophan in the plasma, because we examined too few cases. However, the finding by Ono et al. (19) of high free tryptophan in hepatic encephalopathy of liver cirrhosis suggests that hepatic encephalopathy of liver cirrhosis in their case might be accompanied by bleeding.

The tryptophan concentration in the cerebrospinal fluid (CSF) of cases with hepatic encephalopathy was reported to be significantly higher than that in cases without encephalopathy (19). This increase was believed to be caused by an increase of free tryptophan in the plasma. But our study showed that the plasma tryptophan concentration in liver cirrhosis with encephalopathy but no bleeding tendency was similar to that of controls. Our data are compatible with the fact that a raised value of tryptophan in the CSF is independent of the plasma free tryptophan, because the permeability of the blood brain barrier changes in hepatic encephalopathy $(32,33)$. From extensive studies, Mans et al. (32) concluded that the influx of tryptophan through the blood brain barrier changes with the concentration and composition of competing amino acids; in other words, even when the plasma free tryptophan is not high enough to evoke encephalopathy, prolonged slight encephalopathy may promote the passage of tryptophan through the blood brain barrier into the brain and result in encephalopathy by tryptophan itself. If this is the case, transfusion of excess branched chain amino acids may repress the transport of tryptophan into the brain and be helpful in treatment of encephalopathy. In fact very low tryptophan concentrations in plasma were observed in some hepatic encephalopathy (data not shown).
Hutson et al. (20) reported that after recovery from coma plasma free tryptophan decreased but tryptophan in the CSF remained unchanged. The decrease of plasma free tryptophan may be the result of improvement of liver function, and this improvement may decrease the concentrations of substances that evoke coma to values below those effective in producing coma. The substances producing coma are reported to be 2-oxoglutaramate (2), ammonia (3), free fatty acids (4-7), methylmercaptan (7) and other false neurotransmitters (8-12); these components also act synergistically. We plan to study the effects of amino acid metabolism, mercaptan, ammonia and false transmitters and their mutual relations on the mechanism of the blood brain barrier.

In fluminant hepatitis, whether the total tryptophan is low or high, almost all the tryptophan is free. Since, as far as examined, free fatty acids had no relation with free tryptophan, the binding ability of tryptophan to albumin may change in fulminant hepatitis. In this decrease, though there is some tendency for bleeding, f-Trp/t-Trp ratio is significantly higher than in liver cirrhosis with bleeding, suggesting that the conditions are different from those in liver cirrhosis with bleeding tendency. The relation between bleeding and tryptophan or $\mathrm{f}-\mathrm{Trp} / \mathrm{t}-\mathrm{Trp}$ ratio must be examined in more cases.

As shown in table 5, positive relations of free and total tryptophan to albumin were found in liver cirrhosis, but not in liver cirrhosis with hepatocellular carcinoma. Moreover many correlations of tryptophan with amino acids, and of tryptophan with liver function, were found to be changed in liver cirrhosis when hepatocellular carcinoma was present. These results indicate that liver disease involves changes in metabolism and liver function, which are responsible for the observed changes in the relation between tryptophan and other amino acids, and between tryptophan and liver function. These results indicate that liver disease involves changes in metabolism and liver function, which are responsible for the observed changes in the relationship between tryptophan and other amine acids, and between tryptophan and liver function.

\section{Acknowledgment}

We thank Professor $R$. Kido of Wakayama Medical college for help and encouragement during this work. 


\section{References}

1. Bloxam, D. L. \& Warren, W. H. (1974) Anal. Biochem. 60 , 621-625.

2. Vergara, F., Plum, F. \& Duffy, T. E. (1974) Science 183 , 81-83.

3. Webster, L. T. (1965) Gastroenterology 49, 698-702.

4. Livingstone, A. S., Potvin, M., Goresky, C. A., Finlayson, M. H. \& Hinchey, E. J. (1977) Gastroenterology 73, 697-704.

5. Holmin, T. (1976) Scand. J. Clin. Lab. Invest. 36, 423-429.

6. Derr, R. F. \& Zieve, L. (1973) J. Neurochem. 21, 15551557.

7. Zieve, L., Doizaki, W. \& Zieve, F. J. (1974) J. Lab. Clin. Med. 83, 16-28.

8. Fischer, J. E. \& Baldessarini, R. J. (1971) Lancet II, 75-79.

9. Fernstrom, J. D. \& Wurtman, R. J. (1972) Science 178, 414-416.

10. Dodsworth, J. M., James, J. H., Cummings, M. C. \& Fischer, J. E. (1974) Surgery 75, 811-820.

11. Fischer, J. E., Funovics, J. M., Aguirre, A., James, J. H., Keane, J. M., Wesdorp, R. I. C., Yoshimura, N. \& Westman, T. (1975) Surgery 78, 276-290.

12. Soeters, P. B. \& Fischer, J. E. (1976) Lancet $I I, 880-882$.

13. Ogihara, K., Mozai, T. \& Hirai, S. (1966) New. Eng. J. Med. $275,1255-1256$.

14. Hirayama, C. (1971) Clin. Chim. Acta 32, 191-197.

15. Munro, H. N., Fernstrom, J. D. \& Wurtman, R. J. (1975) Lancet $I, 722-724$.

16. Curzon, G., Kantamaneni, B. D., Winch, J., Rojas-Bueno, A., Murray-Lyon, I. M. \& Williams, R. (1973) J. Neurochem. 21. 137-146.

17. Hijikata, Y., Hara, K., Egawa, H., Mizuno, T., Shiozaki, Y., Murata, K. \& Sameshima, Y. (1981) Anal. Biochem. 118, 10-16.
18. Bauman, P., Duruz, E. \& Heimann, H. (1974) Clin. Chim. Acta $51,35-40$.

19. Ono, J., Hutson, D. G., Dombro, R. S., Levi, J. U., Livingstone, A. \& Zeppa, R. (1979) Gastroenterology 74, 196200.

20. Hutson, D. G., Ono, J., Dombro, R. S., Levi, J. U., Livingstone, A. \& Zeppa, R. (1979) Am. J. Surg. 137, 235-239.

21. Beck, O. \& Hesselgren, T. (1980) J. Chromatography 181, $100-102$.

22. Trey, C., Burns, D. \& Saunders, S. (1966) N. Eng. J. Med. 274, 473-481.

23. Hara, K., Uenishi, E., Ishii, D., Egawa, H., Yasuhara, A. \& Murata, K. (1981) Japan. J. Clin. Chem. 10, 267-273.

24. McMenamy, R. H. \& Oncley, J. L. (1958) J. Biol. Chem. 233, 1436-1447.

25. McMenamy, R. H., Lund, C. C., Marcke, J. \& Oncley, J. L. (1961) Arch. Biochem. Biophys. 93, 135-139.

26. Eccleston, E. G. (1973) Clin. Chim. Acta 48, 269-272.

27. Bloxam, D. L., Hutson, P. H. \& Curzon, G. (1977) Anal. Biochem. 83, 130-142.

28. Kawade, Y. (1981) Acta Sch. Med. Univ. Gifu-GDIKA. 29, 748-785.

29. Knell, A. J., Davidson, A. R., Williams, R., Kantamaneni, B. D. \& Curzon, G. (1974) Br. Med. J. 1, 549-551.

30. Curzon, G., Knott, P. J. \& Murray-Lyon, I. M. (1975) Lancet I, 1092-1093.

31. Pardridge, W. M. (1975) Lancet $I, 1035-1035$.

32. Mans, A. M., Biebuyck, J. F., Saunders, S. J., Kirsch, R. E. \& Hawkins, R. A. (1979) J. Neurochem. 33, 409-418.

33. Livingstone, A. S., Potvin, M., Goresky, C. A., Finlayson, M. H. \& Hinchey, E. J. (1977) Gastroenterology 73, 697-704.

Yoshiko Sameshima

The 3rd Department of Internal Medicine

Kansai Medical University

1 Fumisonocho, Moriguchi

Osaka 570, Japan 
, . 